\title{
Forecasting Tourist Arrivals Using Origin Country Macroeconomics
}

Ioannis Chatziantoniou $^{1^{*}}$, Stavros Degiannakis ${ }^{2,3}$, Bruno Eeckels $^{4}$, George Filis ${ }^{4}$

${ }^{1}$ Portsmouth Business School, Subject Group of Economics and Finance, University of Portsmouth, Portland Street, PO1 3DE, UK

${ }^{2}$ Department of Economics and Regional Development, Panteion University of Social and Political Sciences, 136 Syngrou Avenue, GR17671, Athens, Greece.

${ }^{3}$ Postgraduate Department of Business Administration, Hellenic Open University, Aristotelous 18, 26 335, Greece

${ }^{4}$ Bournemouth University, Department of Accounting, Finance and Economics, Executive Business Centre, 89 Holdenhurst Road, BH8 8EB, Bournemouth, UK

*Corresponding author: email: ioannis.chatziantoniou@port.ac.uk, tel: 0044 (0) 2392 844022, fax: 0044 (0) 2392844037. 


\title{
Forecasting Tourist Arrivals Using Origin Country Macroeconomics
}

\begin{abstract}
This study utilizes both disaggregated data and macroeconomic indicators in order to examine the importance of the macroeconomic environment of origin countries for analysing destinations' tourist arrivals. In particular, it is the first study to present strong empirical evidence that both of these features in tandem provide statistically significant information of tourist arrivals in Greece. The forecasting exercises presented in our analysis show that macroeconomic indicators conducive to better forecasts are mainly origin country-specific, thus highlighting the importance of considering the apparent sharp national contrasts among origin countries when investigating domestic tourist arrivals. Given the extent of the dependency of the Greek economy on tourism income, but also, given the perishable nature of the tourist product itself, results have important implications for policy makers in Greece.
\end{abstract}

Keywords: Tourist arrivals forecasting, seasonal ARIMA, Diebold-Mariano test, disaggregated data, macroeconomic indicators.

JEL Classification: C22, C53, F19, O10. 


\section{Introduction}

The literature has long established the importance of tourism demand forecasting. The consensus is that forecasting tourist arrivals is necessary for tourism planning, policy decision making, as well as, budgeting issues by tourism operators, especially due to the perishable nature of tourism (see, inter alia, Uysal and O'Leary, 1986; Law and Au, 1999; Law, 2000; Chandra and Menezes, 2001). From a macroeconomic point of view, destination's infrastructure and promotion require substantial investment and thus an estimate of the destination's future tourism demand is essential in order to safeguard a positive return on investment. From a microeconomic point of view, forecasting tourism demand is an important tool for the firms that operate in the sector, such as airlines, tour operators, hotels, etc. Finally, tourism forecasting is also necessary as a governmental tool for policy decisions which aim at accelerating economic development that is particularly crucial for countries that heavily depend on tourism income (Goh and Law, 2002; Cho, 2003; Palmer et al., 2006; Song and Witt, 2006; Gounopoulos et al., 2012). Given that important business decisions are based to a great extent on expectations about future market conditions, better ways of forecasting could steer both public and private decisions to more efficient and effective paths; thus, benefiting the country as a whole.

Our analysis of tourism demand puts heavy emphasis on the employment of a broader set of macroeconomic indicators of origin countries. Although there have been studies to investigate tourism demand by country of origin (see, among others, Nicolau and Mas, 2005a,b; Wang et al., 2006; Rudez, 2008; Lim et al., 2009; Alegre et al., 2010) most of these studies have mainly focused on income of the origin country or/and on the relative price levels (i.e. a relatively narrow set of macroeconomic indicators of origin countries). At the same time, none of these studies has incorporated such a set of macroeconomic indicators specifically for the purposes of forecasting tourism demand. In this study, we argue that employing a variety of macroeconomic indicators might, in fact, lead to a better understanding of the forces that drive decisions in origin countries, as well as, improve the forecasting of tourism demand in destination countries. This is in line with Song et al. (2011) who argue in support of the development of models which incorporate a broader set of explanatory variables to explain the dynamics that drive tourism demand. Another key aspect of this study is that contrary to existing endeavours which have mainly concentrated on producing forecasts of tourism demand 
using a Vector Autoregressive (VAR) framework, it employs the SARIMA-type models which according to recent relevant literature tend to generate superior forecasts.

In turn, the contributions of this paper are described succinctly. First, we employ a country-of-origin approach in order to forecast tourism demand in Greece. Second, we forecast tourism demand based on both aggregated and disaggregated data on inbound tourist arrivals, using SARIMA-type models and we augment this specification by employing macroeconomic indicators of origin countries as explanatory variables. The present work constitutes an extension of existing literature in this area, as it is the first to employ both disaggregated data and macroeconomic indicators in tandem for the purpose of forecasting tourist arrivals.

Our forecasting exercises show that investigating tourism demand in Greece by considering macroeconomic indicators by country of origin offers an additional tool to decision makers (such as tourism policy makers and tourism providers in Greece) as it informs their practices and improves their forecasts. From a technical perspective, based on the Diebold-Mariano test, we show that the SARIMA specification which uses both disaggregated tourist arrivals data and macroeconomic variables does provide statistically significantly better forecasts compared to the SARIMA specification based on the aggregated tourist arrivals data. Results are very important, considering the perishable nature of the tourist product which renders necessary the choice of the best model to forecast tourist arrivals. In effect, this study serves as a new tool to policy makers and tourism businesses on how they should assess the macroeconomic developments in the tourism origin countries when planning the Greek tourism strategy and predicting future tourism earnings.

The rest of the paper is structured as follows. In section 2 we present a brief review of the existing literature. Section 3 describes the data, whereas Section 4 illustrates the forecasting models and provides a detailed explanation of the forecasting estimation procedure. Section 5 describes the adopted forecasting evaluation method. Section 6 analyses the empirical findings, before Section 7 concludes the study.

\section{Brief review of the literature}

It falls beyond the scope of this study to offer an extensive review of the related literature. However, it would be instructive at this point to overview certain key aspects raised in previous studies in order to position our research in this crowded literature. To 
this end, in the following paragraphs, we outline succinctly considerations which are mainly associated with the type of data, the model and its specification.

To begin with, we approximate tourism demand by tourism arrivals (i.e. in line with authors such as Dharmaratne, 1995; Smeral and Weber, 2000; Law, 2000; Burger et al., 2001; Lim and McAleer, 2001a,b; Song and Witt, 2006; Athanasopoulos and Hyndman, 2008; Shen et al., 2011; Gounopoulos et al., 2012). Furthermore, contrary to the majority of the existing literature and yet in accordance with authors such as Kim and Moosa (2005) and Wan et al. (2013), we employ disaggregated data to forecast tourism demand as we also believe that this approach could provide policy makers with more detailed and diverse information.

Turning to the type of models employed by existing literature, we observe that not a single model is preferred. In fact, a battery of different models has been applied, such as (i) ARIMA (Autoregressive Integrated Moving Average) models ${ }^{1}$, (ii) ECM (Error Correction Model) and VAR (Vector Autoregressive) models ${ }^{2}$, (iii) ADL (Autoregressive Distributed Lag) models ${ }^{3}$, (iv) TVP (Time-Varying Parameter) models (Song et al., 2003), as well as, (v) Holt-Winters and other exponential smoothing methods ${ }^{4}$.

Despite the non-consistent findings in terms of the best performing model used to forecast tourism demand, it seems that the most widely used and successful are the ARIMA-type models. Furthermore, one specific version of the ARIMA models, that of Seasonal ARIMA (SARIMA), has attracted considerable attention over the years due to its good performance which can be attributed to its ability to capture the seasonal character of tourism demand variables (see, indicatively, Song and Li, 2008; Brida and Risso, 2011; Hadavandi et al. 2011).

Next, we concentrate on studies which employ macroeconomic indicators in their analysis of tourism demand. It should be noted that a remarkable number of studies concentrate on the impact of macroeconomic indicators of origin countries on tourism demand at destination countries. For its most part though, literature in this field has

\footnotetext{
${ }^{1}$ See, inter alia, Kulendran and Wilson, 2000; Cho, 2001; Lim and McAleer, 2001a; Goh and Law, 2002; Cho, 2003; Kulendran and Witt, 2003; Chen, 2005; Vu and Turner, 2005; Kim and Moosa, 2005; Vu and Turner, 2006; Wong et al., 2007; Coshall, 2009; Santos, 2009; Brida and Risso, 2011; Gounopoulos et al., 2012; Zheng et al., 2012; Wan et al., 2013.

${ }^{2}$ See for instance, Kulendran and Wilson, 2000; Song and Witt, 2000; Kulendran and Witt, 2003; Song and Witt, 2006; Wong et al., 2006; Wong et al., 2007.

${ }^{3}$ See indicatively, Song et al., 2003; Wong et al., 2007.

${ }^{4}$ See, for example, Lim and McAleer, 2001b; Chen, 2005; Vu and Turner, 2005; Yu et al., 2007; Zheng et al., 2012.
} 
focused on demand factors and especially income (see, among others, Nicolau and Mas, 2005a,b; Wang et al., 2006; Rudez, 2008; Lim et al., 2009; Alegre et al., 2010). This is mainly due to the fact that tourism is regarded as a luxury good and as such, it is expected to be heavily dependent on income (Chatziantoniou et al., 2013; Wang, 2014). In short, the main finding of all these studies is that the level of income appears to exert a significant influence on tourism expenditure.

In support of this view, authors such as Papatheodorou et al. (2010), Page et al. (2012), as well as, Eugenio-Martin and Campos-Soria (2014) report negative effects on demand for tourism during periods of recession. Focusing on Greece, Dritsakis (2004) and Gounopoulos et al. (2012) emphasize income and unemployment (i.e. leading to loss of income) respectively, as two major indicators affecting demand for tourism in Greece. There is no doubt that income is indeed a key macroeconomic variable in the investigation of tourism demand.

Exchange rates constitute one additional demand factor typically employed by tourism demand studies. In general, evidence suggests that the level of the exchange rate can be credited with changes in the level of inbound tourism flows (see, inter alia, Bull, 1995; Hiemstra and Wong, 2002; Croes and Vanegas, 2005; Prideaux, 2005; Algieri, 2006; Saayman and Saayman, 2008; Wang, 2009). It should be noted that exchange rates can be also approximated by inflation differentials, on the basis of the Purchasing Power Parity notion. In this regard, Chang et al. (2013) point out that in the light of rises in inflation within the country of origin travellers typically contain their outbound tourism expenditure. This is anticipated, given that increased inflation weakens the domestic currency. Gounopoulos et al. (2012) investigate whether inflation differentials between origin and destination countries can influence inbound tourism. Results for Greece indicate that there is indeed a negative relation.

Demand for tourism can also be related to expectations about future economic conditions. According to authors such as Bull (1995) and Prideaux (2005) the Government has a key role to play in fashioning broader economic conditions and influencing expectations. Authors such as Kim et al. (2012) place heavy emphasis upon the effect of expectations about future income on demand for outbound tourism. It is important to note at this point that expectations about the future economic conditions can be reflected upon popular survey measures, such as the consumer confidence indicator (see, for example, Ludvigson, 2004). In close relation to this, authors such as Taylor and McNabb (2007) argue that both the consumer and the business confidence 
indicators have a key role to play in predicting recessions. Gounopoulos et al. (2012) also employ the consumer confidence index of origin countries as an approximation of their general economic conditions and investigate whether there is an impact on inbound Greek tourism.

Overall, in contrast with the narrow perspective usually encountered in existing literature, our study considers a broader set of macroeconomic indicators, comprising five macroeconomic indicators; namely, income, price level differentials, consumer confidence index, business confidence index, as well as, economic policy uncertainty (PUI) index. These indicators are specifically constructed to capture expectations about future economic conditions. To the effect that we make use of the ratio of domestic to foreign inflation rate (price level differential) we account for exchange rate issues, as well. With reference to the economic policy uncertainty index, this is developed by Baker et al. (2013) and has recently gained much prominence, as it is considered to be a very robust measure of policy-related uncertainty at both the fiscal and the monetary policy level (see, inter alia, Leduc and Liu, 2012; Antonakakis et al., 2013; Colombo, 2013; Kang and Ratti, 2013; Pastor and Veronesi, 2013). By considering this relatively extensive set of macroeconomic indicators which could potentially influence inbound tourism demand, we aim to produce more accurate forecasts regarding inbound tourist arrivals in Greece from seven key origin countries.

\section{Data description}

In this study we use monthly tourist arrivals in Greece from seven key origin countries, namely, Canada, France, Germany, Italy, Spain, the UK and the US for a period extending from January 2003 to June 2013. In addition, we consider monthly macroeconomic variables for each of these countries. These variables are industrial production (IP) index, consumer price index (CPI), consumer confidence (CC) index, business confidence (BC) index and economic policy uncertainty (PUI) index.We also consider the Greek consumer price index, which is used to estimate the consumer price differentials between Greece and the origin countries. Consumer price differentials are estimated as $C P D_{t}=C P I_{G R, t} / C P I_{O C i, t}$, where $G R$ denotes the Greek CPI and $O C i$ stands for the CPI of the origin country $i$. Macroeconomic variables are denoted as $x_{t}^{(j)}$ , for $j=1, \ldots, 5$, in the analysis. The selection of the macroeconomic variables is based on the criteria set out in Section 2. The choice of countries is influenced by two factors, 
namely that the countries of origins should be among the top countries of origin for Greece and that they should have data on the chosen macroeconomic variables.

Tourist arrivals data are obtained from Bank of Greece, data on economic policy uncertainty index are taken from Baker et al. (2013), whereas all other data on the remaining macroeconomic variables were extracted from Datastream ${ }^{\circledR}$. The period of study is motivated by the data availability. The total number of months is $T=126$. Based on a starting sample of $\hat{T}=37$ observations, a total of $h=T-\hat{T}=89$ out-of-sample monthly forecasts consist the forecasting period (February 2006-June 2013) ${ }^{5}$. Descriptive statistics, as well as, plots of the variables under investigation are given in Table 1 and Figures 1, 2 and 3, respectively.

\section{[TABLE 1 HERE] \\ [FIGURE 1 HERE] \\ [FIGURE 2 HERE] \\ [FIGURE 3 HERE]}

Table 1 and Figure 1 suggest that, on average, for the study period, tourist arrivals in Greece from the chosen countries of origin contribute about $43 \%$ of the total tourist arrivals. This figure is even higher during the peak months of Greek tourism (i.e. from June until October) when the contribution of these countries to the total tourist arrivals fluctuates between $45 \%$ and $61 \%$. These values signify the importance of these seven countries to the Greek tourism sector. Country-wise, we observe that Greece mainly attracts tourists from France, Germany, Italy and the UK.

Furthermore, Table 1 and Figures 1 and 2 provide evidence for the distributional and statistical properties of the variables under investigation. All tourist arrivals series $\left(y_{t}\right)$ are non-stationary with a strong seasonal pattern ${ }^{6}$. Additionally, the first difference

\footnotetext{
${ }^{5}$ More specifically, the first estimation period of the models is $\hat{T}=37$ months, i.e. from January 2003 until January 2006. The remaining $h=89$ months of our sample size are used for the evaluation period of the out-of-sample forecasts. In order to proceed to the first out-of-sample forecast (i.e. $t+1$ forecast or month 38) we estimate the models using the initial 37 months. For each subsequent out-of-sample forecast we add to the estimation period an additional month. For example, for the $t+2$ forecast we use $\hat{T}+1$ monthly observations. The total number of observations is $T=\hat{T}+h$. The out-of-sample phase has been selected in order to capture the period before, during and after the global financial crisis (as well as the Greek debt crisis).

${ }^{6}$ We have also used the HEGY unit root test (Hylleberg et al., 1990) and we find that the seasonal component of our series is stationary. Furthermore, we extract the seasonal component from our series using the TRAMO/SEATS procedure and we run unit root tests on the de-seasonlised series and the seasonal factor. The tests confirm that the series is non-stationary with a stationary seasonal component. Results are available upon request.
} 
of the logarithmic transformation, $(1-L)\left(\log y_{t}\right)$, has a statistically significant autocorrelation pattern. In particular, the autocorrelation analysis confirms the existence of statistically significant autocorrelation and partial autocorrelation ${ }^{7}$; i.e. Box and Jenkins (1970), Box et al. (2008), Brockwell and Davis (2009), Ljung and Box (1978). Furthermore, the unit root tests show that the log-differences of monthly tourist arrivals are stationary. This holds for both the aggregate data, as well as, the disaggregated data by origin country. Therefore, the most appropriate model for the estimations is a SARIMA-type model.

Figure 3 shows the five macroeconomic variables which are employed in this study. We observe that the chosen indices are able to capture the economic conditions of the origin countries. For instance, the business confidence, consumer confidence and industrial production indices exhibit a clear trough in the Great Recession of 2007-09, whereas the economic policy uncertainty index reaches a peak during the same economic crisis. Similarly, the CPI differentials show a decreasing trend during the latter part of the study period, which coincides with the debt crisis in Greece and results in the significant reduction of the country's consumer price index.

\section{Models' Specification}

The purpose of this study is the evaluation of the forecasting accuracy of three different model specifications (i.e. forecasting exercises). First we forecast total tourist arrivals in Greece from the seven origin countries based on aggregate data (first specification). Next we forecast total tourist arrivals from these countries based on the disaggregated data by origin country (second specification). Finally, we forecast total tourist arrivals based on the disaggregated data by origin country and exploiting the predictive information provided by the exogenous macroeconomic variables (third specification).

The statistically significant autocorrelation pattern, the seasonality of the monthly data and the first-order integrated character of logarithmic transformation of tourist arrivals are best described by a $\operatorname{SARIMA}(k, 1, l)\left(k^{\bullet}, l^{\bullet}\right)$ model $^{8}$. Therefore, we estimate a set of SARIMA models for various orders of $k, l, k^{\bullet}, l^{\bullet}$, and more

\footnotetext{
${ }^{7}$ The results are available upon request.

${ }^{8}$ The $k$ and $l$ denote the number of lags for the autoregressive and the moving average polynomials, respectively. The $k^{*}$ and $l^{*}$ denote the number of lags for the seasonal autoregressive and the seasonal moving average polynomials, respectively.
} 
specifically for $k=0,1,2, l=0,1,2, k^{\bullet}=0,1,2, l^{\bullet}=0,1,2$. In total, 81 variations of the $\operatorname{SARIMA}(k, 1, l)\left(k^{\bullet}, l^{\bullet}\right)$ model are estimated recurrently at each month for the out-ofsample period ${ }^{9}$.

The incorporation of exogenous information (inclusion of macroeconomic variables) is utilized with the estimation of $\operatorname{SARMAX}(k, l)\left(k^{\bullet}, l^{\bullet}\right)$ models, where $\mathrm{X}$ denotes the use of exogenous variables. The SARMAX models combine the autocorrelated and seasonal pattern of log-tourist arrivals with the information extracted exogenously from the macroeconomic variables. Therefore, we estimate a set of $\operatorname{SARMAX}(k, l)\left(k^{\bullet}, l^{\bullet}\right)$ models for various orders of $k, l, k^{\bullet}, l^{\bullet}$, and more specifically for $k=0,1,2, l=0,1,2, k^{\bullet}=0,1,2, l^{\bullet}=0,1,2$. For each exogenous macroeconomic variable, $x_{t}^{(j)}$, for $j=1, \ldots, 5,81$ variations of the $\operatorname{SARMAX}(k, l)\left(k^{\bullet}, l^{\bullet}\right)$ model are estimated recurrently at each month for the out-of-sample period. Thus, in total 405 SARMAX specifications are estimated for each of the $h=89$ out-of-sample months.

\subsection{Seasonal Autoregressive Integrated Moving Average Model-SARIMA $(k, 1, l)$ $\left(k^{\bullet}, l^{\bullet}\right)$ Model}

The Seasonal Autoregressive Integrated Moving Average Model with orders ( $k, 1, l)$ and $\left(k^{\bullet}, l^{\bullet}\right)$, or $\operatorname{SARIMA}(k, 1, l)\left(k^{\bullet}, l^{\bullet}\right)$ is defined as ${ }^{10,11}$ :

$$
(1-A(L))(1-C(L))\left((1-L)\left(\log y_{t}\right)-\beta_{0}\right)=(1+B(L))(1+D(L)) \varepsilon_{t},
$$

where $A(L)=\sum_{i=0}^{k} a_{i} L^{i}, C(L)=\sum_{i=0}^{k^{*}} c_{i} L^{12 i}, B(L)=\sum_{i=0}^{l} b_{i} L^{i}, D(L)=\sum_{i=0}^{l^{*}} d_{i} L^{12 i}, L$ is the lag operator, $a_{0}=c_{0}=b_{0}=d_{0}=0, a_{1}, \ldots, a_{k}, c_{1}, \ldots, c_{k^{*}}, b_{1}, \ldots, b_{l}, d_{1}, \ldots, d_{l^{*}}, \beta_{0}$ are parameters for estimation, and $\varepsilon_{t} \sim N\left(0, \sigma_{\varepsilon}^{2}\right)$.

\footnotetext{
${ }^{9}$ The certain parameter ranges of AR and MA orders for both seasonal and non-seasonal components rely on methods of orders' selection (Schwarz's, 1978 and Akaike's, 1974 information criteria) and correlogram diagnostics. We use the information criteria in order to set the upper bounds for the ranges of the dynamics included in the models.

${ }^{10}$ Originally the model is denoted as $\operatorname{SARIMA}(k, 1, l)\left(k^{\bullet}, 0, l^{\bullet}\right)$, but for simplicity we have removed the zero term. The proposed framework can be defined either as a SARMA specification for the dependent variable $(1-L)\left(\log y_{t}\right)$ or as a SARIMA specification for the dependent variable $\log y_{t}$. In the latter case, the models can be stated as SARIMA with integrated order I(1), or $\operatorname{SARIMAX}(k, 1, l)\left(k^{*}, l^{*}\right.$ ) .

${ }^{11}$ The log transformation stabilizes the variance of $y_{t}$, thus, it is preferred; see i.e. Lütkepohl and Xu (2012). The models' integration order is set to 1 . For higher order of integration the forecasting accuracy deteriorates significantly.
} 
The one-month-ahead tourist arrivals prediction by $\operatorname{SARIMA}(k, 1, l)\left(k^{\bullet}, l^{\bullet}\right)$ is computed as:

$$
\begin{aligned}
& y_{t+1 \mid t}= \\
& =\exp \left(\begin{array}{c}
(C(L)+A(L)-A(L) C(L))\left((1-L)\left(\log y_{t+1}\right)-\beta_{0}\right) \\
+(D(L)+B(L)+B(L) D(L)) \varepsilon_{t+1}+0.5 \sigma_{\varepsilon}^{2(t)}
\end{array}\right)
\end{aligned}
$$

where $\quad A(L)=\sum_{i=1}^{k} a_{i} L^{i}, \quad C(L)=\sum_{i=1}^{k^{*}} c_{i} L^{12 i}, \quad B(L)=\sum_{i=1}^{l} b_{i} L^{i}, \quad D(L)=\sum_{i=1}^{l^{*}} d_{i} L^{12 i}$.As, $\varepsilon_{t} \sim N\left(0, \sigma_{\varepsilon}^{2}\right)$, the $\exp \left(\varepsilon_{t}\right)$ is log-normally distributed, therefore the one-month-ahead tourist arrivals prediction is adjusted as $y_{t+1 \mid t}=\exp \left(\log \left(y_{t+1 \mid t}\right)+0.5 \sigma_{\varepsilon}^{2(t)}\right)$.

\subsection{Seasonal Auto-Regressive Moving Average Model with Exogenous Variables-}

\section{$\operatorname{SARMAX}(k, l)\left(k^{\bullet}, l^{\bullet}\right)$ Model}

The Seasonal Autoregressive Moving Average Model including exogenous variables with orders $(k, l)$ and $\left(k^{\bullet}, l^{\bullet}\right)$, or $\operatorname{SARMAX}(k, l)\left(k^{\bullet}, l^{\bullet}\right)$ is defined as:

$$
(1-A(L))(1-C(L))\left(\left(\log y_{t}\right)-\beta_{0}-\beta_{1}\left(\log x_{t-1}^{(j)}\right)\right)=(1+B(L))(1+D(L)) \varepsilon_{t},
$$

where $A(L)=\sum_{i=0}^{k} a_{i} L^{i}, C(L)=\sum_{i=0}^{k^{*}} c_{i} L^{12 i}, B(L)=\sum_{i=0}^{l} b_{i} L^{i}, D(L)=\sum_{i=0}^{l^{*}} d_{i} L^{12 i}, L$ is the lag operator, $a_{0}=c_{0}=b_{0}=d_{0}=0, a_{1}, \ldots, a_{k}, c_{1}, \ldots, c_{k^{*}}, b_{1}, \ldots, b_{l}, d_{1}, \ldots, d_{l^{*}}, \beta_{0}, \beta_{1}$ are parameters for estimation, and $\varepsilon_{t} \sim N\left(0, \sigma_{\varepsilon}^{2}\right)$. The exogenous variables $x_{t}^{(j)}$, for $j=1, \ldots, 5$ are incorporated into the model in a lagged term in order to provide forecasting information.

The one-month-ahead tourist arrivals prediction by a $\operatorname{SARMAX}(k, l)\left(k^{\bullet}, l^{\bullet}\right)$ is computed as:

$$
\begin{aligned}
& y_{t+1 \mid t}= \\
& =\exp \left(\begin{array}{c}
\beta_{0}+\beta_{1}\left(\log x_{t}^{(j)}\right)+ \\
(C(L)+A(L)-A(L) C(L))\left(\left(\log y_{t+1}\right)-\beta_{0}-\beta_{1}\left(\log x_{t}^{(j)}\right)\right) \\
+(D(L)+B(L)+B(L) D(L)) \varepsilon_{t+1}+0.5 \sigma_{\varepsilon}^{2(t)}
\end{array}\right)
\end{aligned}
$$

where $A(L)=\sum_{i=1}^{k} a_{i} L^{i}, C(L)=\sum_{i=1}^{k^{*}} c_{i} L^{12 i}, B(L)=\sum_{i=1}^{l} b_{i} L^{i}, D(L)=\sum_{i=1}^{l^{*}} d_{i} L^{12 i}$.

For example, the forecast from the $\operatorname{SARMA}(1,1)(0,1)$ model is computed as: 


$$
y_{t+1 \mid t}=\exp \left(\begin{array}{c}
\beta_{0}+\beta_{1} \log x_{t}^{(j)}+\log x_{t-1}^{(j)}+a_{1} \log y_{t}-a_{1} \beta_{0}-a_{1} \beta_{1} \log x_{t-1}^{(j)} \\
+d_{1} \varepsilon_{t-1 \mid t}+b_{1} \varepsilon_{t \mid t}+b_{1} d_{1} \varepsilon_{t-12 \mid t}+0.5 \sigma_{\varepsilon}^{2(t)}
\end{array}\right),
$$

where $\varepsilon_{t-t^{*} \mid t}$ denotes the residual term at time $t-t^{*}$ estimated based on the information set at time $t$.

\subsection{Forecasting Total Tourist Arrivals (SARIMA Specification)}

The $\operatorname{SARIMA}(k, 1, l)\left(k^{\bullet}, l^{\bullet}\right)$ specification is used to forecast the total number of tourist arrivals from the seven origin countries under investigations. Equation (1) is considered for $y_{t}$ denoting the total tourist arrivals. From 81 variations of the $\operatorname{SARIMA}(k, 1, l)\left(k^{\bullet}, l^{\bullet}\right)$ model, the orders $k, l, k^{\bullet}, l^{\bullet}$ with the minimum value of the forecasting evaluation criteriain the out-of-sample period are selected (see Equations 6 and 7).

\subsection{Forecasting Tourist Arrivals per Origin Country (Composite SARIMA Specification)}

The SARIMA $(k, 1, l)\left(k^{\bullet}, l^{\bullet}\right)$ specification is used to forecast the number of tourist arrivals from each of the seven origin countries separately. Equation (1) is considered for $y_{t}$ denoting the tourist arrivals from each country separately. The forecast of the total tourist arrivals is the sum of the forecasts of tourist arrivals from each country. For each country, out of the 81 variations of the $\operatorname{SARIMA}(k, 1, l)\left(k^{\bullet}, l^{\bullet}\right)$ model, the orders $k, l, k^{\bullet}, l^{\bullet}$ that minimize the forecasting evaluation criteriain the outof-sample period are selected.

\subsection{Forecasting Tourist Arrivals per Origin Country Incorporating Information from Macroeconomic Variables (Composite SARMAX Specification)}

The $\operatorname{SARMAX}(k, l)\left(k^{\bullet}, l^{\bullet}\right)$ specification is used to forecast the number of tourist arrivals from each of the seven countries separately. Equation (3) is considered for $y_{t}$ denoting the tourist arrivals from each country separately, and with the incorporation of exogenous variables $x_{t}^{(j)}$. The forecast of the total tourist arrivals is the sum of the forecasts of tourist arrivals from each country. 
The 81 variations of the $\operatorname{SARMAX}(k, l)\left(k^{\bullet}, l^{\bullet}\right)$ model are estimated for each of the 5 explanatory economic variables, $x_{t}^{(j)}$, for $j=1, \ldots, 5$. Hence, in total for each country of origin, we estimate $5^{*} 81=405 \operatorname{SARMAX}(k, l)\left(k^{\bullet}, l^{*}\right)$ specifications. Each of the 405 SARMAX specifications are estimated for $h=89$ out-of-sample months. For each country, from the $405 \operatorname{SARMAX}(k, l)\left(k^{\bullet}, l^{\bullet}\right)$ variations, the orders $k, l, k^{\bullet}, l^{\bullet}$ and the $x_{t}^{(j)}$ with the minimum value of the forecasting evaluation criteriain the out-ofsample period are selected.

Table 2 presents the $\operatorname{SARIMA}(k, 1, l)\left(k^{\bullet}, l^{\bullet}\right)$ and $\operatorname{SARMAX}(k, l)\left(k^{\bullet}, l^{\bullet}\right)$ specifications that minimize the forecasting evaluation criteria.

[TABLE 2 HERE]

\section{Evaluation Framework}

In this study we use two forecasting evaluation criteria, which are computed in the following form:

$$
\begin{gathered}
\text { Predicted Root Mean Squared Error: } \sqrt{h^{-1} \sum_{t=1}^{h}\left(y_{t+1}-y_{t+1 \mid t}\right)^{2}}, \\
\text { Predicted Mean Absolute Error: } h^{-1} \sum_{t=1}^{h}\left|y_{t+1}-y_{t+1 \mid t}\right|,
\end{gathered}
$$

where $y_{t+1 \mid 1}$ denotes the one-month-ahead forecast of tourist arrivals, and $h$ is the number of months in the out-of-sample period.

In addition, the statistical significance of the forecasts is investigated by the Diebold and Mariano (1995) statistic. Let us denote as $\Psi_{t(A)}$ the value of an evaluation criterion $\Psi$, for month $t$, based on the forecast of model $\mathrm{A}^{12}$.The evaluation differential $\Psi_{t(A, B)}=\Psi_{t(A)}-\Psi_{t(B)}$ defines the difference of evaluation criteria of two competing models; i.e. models A and B. Diebold and Mariano (1995) proposed testing the null hypothesis, $H_{0}: E\left(\Psi_{t(A)}-\Psi_{t(B)}\right)=0$, that two models are of equivalent predictive ability against the alternative hypothesis, $H_{1}: E\left(\Psi_{t(A)}-\Psi_{t(B)}\right)<0$, that model A is of

\footnotetext{
${ }^{12}$ I.e., for the case that the evaluation criterion $\Psi$ is the Root Mean Squared Error,then $\Psi_{t}=\left(y_{t+1}-y_{t+1 \mid t}\right)^{2}$
} 
superior predictive ability compared to its competitor model B. The DM statistic for testing the null hypothesis is estimated as:

$$
D M_{(A, B)}=\frac{\bar{\Psi}_{(A, B)}}{\sqrt{V\left(\bar{\Psi}_{(A, B)}\right)}} .
$$

The average of evaluation differential is $\bar{\Psi}_{(A, B)}=h^{-1} \sum_{t=1}^{h} \Psi_{t(A, B)}$ and a consistent estimate of the variance of $\bar{\Psi}_{(A, B)}$ is computed as $V\left(\bar{\Psi}_{(A, B)}\right)=h^{-1} 2 \tilde{y}_{d}(0)$, where $f_{d}(0)=(2 \pi)^{-1} \sum_{i=-\infty}^{\infty} \gamma_{d}(i)$ is the spectral density of the loss differential at frequency zero.

The DM statistic is approximately normally distributed for large samples of out-ofsample predictions, $h$. The DM statistic is also estimated as the standardized constant coefficient from regressing $\Psi_{t(A, B)}$ on a constant with heteroskedastic and autocorrelated consistent standard errors in the sense of Newey and West (1987). More information about the estimation of the Diebold-Mariano statistic is available in Xekalaki and Degiannakis (2010, pp. 387).

A negative sign of the DM statistic informs that model $\mathrm{A}$ is more accurate compared to model $\mathrm{B}$. The $p$-value informs about the statistical significance between the forecasting accuracy of the competing models.

\section{Empirical Findings}

We consider the forecasting performance of three different model specifications, as described in Sections 4.3 to 4.5. Table 2 reports the results from the RMSE and MAEforecasting evaluation criteriafor each specification.

Table 2 shows that the highest forecasting error is observed in the forecasts made using the aggregate tourist arrivals data (SARIMA specification), with RMSE of 74,035 and MAE of 51,893. The composite forecasting based on the disaggregated data by the origin countries (composite SARIMA specification) is exhibiting a lower forecasting error, given that the RMSE is 69,296 and the MAE is 50,282. However, most prominent among these results is the finding that the lowest forecasting error is observed in the composite forecasts based on the disaggregated data with the use of 
exogenous macroeconomic variables (composite SARMAX specification), with $\mathrm{RMSE}=62,733$ and $\mathrm{MAE}=45,711^{13}$

Furthermore, we notice that both RMSE and MAE are lower for each countryspecific forecast, although this does not hold true for the US. Another interesting finding reported in Table 2 is the fact that there is not a single macroeconomic variable that significantly improves the forecasting ability of the models. In fact, we observe that this is country specific, as for example, the best composite SARMAX specification for Canada is the one that include the consumer confidence index, whereas the best specification for Spain is the one that incorporates the industrial production index.

Next, we assess the best performing model based on the DM test. More specifically, Tables 3 and 4 present the DM statistic estimates for the $\Psi_{t}=\left(y_{t+1}-y_{t+1 \mid t}\right)^{2}$ and $\Psi_{t}=\left|y_{t+1}-y_{t+1 \mid t}\right|$ evaluation criteria, respectively.

\section{[TABLE 3 HERE]}

\section{[TABLE 4 HERE]}

As aforementioned, the null hypothesis of the DM testis that two models are of equivalent predictive ability, whereas the alternative hypothesis is that model $\mathrm{A}$ is of superior predictive ability compared to its competitor model B.

In all cases and for both loss functions the DM statistic in negative, implying that model A generates better forecasts than model B. Nevertheless, not all differences are significant. In particular, the tourist arrivals forecast from the composite SARIMA specification is not statistically more accurate compared to the SARIMA forecast. In addition, the tourist arrivals forecast from the composite SARMAX specification is not significantly more accurate compared to the forecast from the composite SARIMA specification. However, the most important finding is that the forecast of tourist arrivals from the composite SARMAX specification is statistically more accurate compared to the forecast from the SARIMA specification. Therefore, the DM statistics and their associated $p$-values reveal that the inclusion of economic variables in a SARIMA-type model provides tourist arrivals forecasts with statistically superior predictive ability.

Finally, we present the scatter plots in Figures 4 which provide a visual representation of the relationship between actual and predicted tourist arrivals.

\footnotetext{
${ }^{13}$ Typical in forecasting studies is the comparison of candidate models with simple benchmark models; i.e. with/without drift random walk model, $1^{\text {st }}$ order autoregressive model, etc. In our study, the forecasting ability of the naive benchmark models is statistically inferior. The results are available upon request.
} 
[FIGURE 4 HERE]

It is clear from Figure4 that the composite forecast of tourist arrivals from composite SARMAX modelsproduces a rather slimmer plot (see the right panel of Figure4), as opposed to the plots produced by the forecast of the SARIMA and composite SARIMA specifications (see left and central panels, respectively). In addition, thecomposite forecast of tourist arrivals from composite SARMAX specification is observed to have fewer outliers.

\section{Concluding remarks and policy implications}

The aim of this study is to forecast, using SARIMA -type models, the one-month ahead tourist arrivals in Greece based on aggregate tourist arrivals data, disaggregated data by origin country, as well as, a set of macroeconomic indicators from the origin countries as explanatory variables. Our data comprise monthly tourist arrivals in Greece from seven key origin countries, namely, Canada, France, Germany, Italy, Spain, the UK and the US and the period of the study runs from January 2003 until June 2013. The monthly macroeconomic variables for each of these origin countries are, (i) the industrial production (IP) index, (ii) the consumer price level differentials between Greece and the origin country (CPD), (iii) the consumer confidence (CC) index, (iv) the business confidence (BC) index and (v) the economic policy uncertainty (PUI) index.

More specifically, in this study we first forecast total tourist arrivals in Greece from the seven origin countries based on aggregate data (SARIMA specification). Then, we forecast total tourist arrivals from these countries based on the disaggregated data by origin country (composite SARIMA specification). Finally, we forecast total tourist arrivals using the disaggregated data and incorporating exogenous macroeconomic variables (composite SARMAX specification). This is the first study to assess the forecasting accuracy of each SARIMA specification using the Diebold-Mariano test, based on two forecasting evaluation criteria, i.e. Predicted Root Mean Squared Error (RMSE) and Predicted Mean Absolute Error (MAE).

Prominent among the findings of the study is the fact that the origin of tourist arrivals is indeed a crucial factor when it comes to forecasting tourism demand. To be more explicit, results show that in each origin country, there is one single macroeconomic indicator which eventually stands out and can be conducive to better forecasts, while at the same time, this indicator may in fact vary among origin countries. 
In this regard, we note that the consumer confidence index is important for producing better forecasts in Canada and the UK. By the same token, the price level is important for France and Germany, income is important for Italy and Spain, while economic policy uncertainty is important for the US. Thus, this study stresses the importance to incorporate a strenuous set of macroeconomic indicators by origin country as this apparently leads to better forecasts and better decisions.

Considering Greece, this finding is associated with several layers of analysis. First, with the exception of the business confidence indicator, all other indicators are rather crucial at predicting tourist arrivals in Greece. It follows, that policy makers who wish to produce better forecasts - at the aggregate level - may implement most of the indicators included in this study.

Second, at the country-specific level, policy makers could attain a rough yet strong indication about prospective tourist arrivals per origin country by simply considering the changes in the respective macroeconomic variables. For example, on the basis that higher levels of consumer confidence are typically related to higher demand for outbound tourism, monitoring the consumer confidence index in either Canada or the UK could provide useful predictive information regarding future arrivals of both Canadian and British tourists in Greece.

Third, given that outbound tourism factors are country-specific; this finding further exposes the necessity for policy makers to diversify their sources of tourism, as well as, their promoting activities. For example, given that price levels are important in terms of predicting tourist arrivals in Greece from France and Germany, high levels of inflation within the EMU should be accompanied by an effort from policy makers in Greece to convince potential French and German tourists that Greece can be a relatively low-cost destination. It should be noted however, that adopting the appropriate strategy is not always as straightforward as in the case of relative prices. To illustrate this point, we refer to our results for Italy and Spain. In particular, we find that the industrial production index in both countries is a key factor in producing better forecasts regarding tourist arrivals in Greece. A worsening of the industrial production index might lie on more persistent unfavourable developments in an economy - compared to a rise in the level of prices, which can be temporary - suggesting that policy makers in Greece will probably not be able to successfully attract tourists from these two countries by simply offering more competitive prices. However, this reverts back to our initial argument 
that diversifying the sources of tourism and/or promoting activities should indeed be a cardinal strategic objective.

Turning to the forecasting method itself, our forecasting exercises show that the composite SARMAX specification does provide statistically significantly better forecasts compared to the SARIMA specification. This finding holds for both loss functions. Another important finding that is reported in this study is the fact that there is not a single macroeconomic variable that significantly improves the forecasting ability of the models. In fact, the best variable is country specific; as for example, the best composite SARMAX specification for Canada is the one that includes the consumer confidence index, whereas the best performing specification for Spain is the one that incorporates the industrial production index.

Tourism is a key economic activity in Greece and a major source of domestic income with direct implications regarding its influence on the country's overall growth potential. This fact underscores the necessity for accurate tourist arrivals forecasts. The tourist product has a perishable nature and therefore, the choice of the best model is of major importance. Thus, our findings have important implications when it comes to developing the appropriate tourism strategy plan.

In retrospect, policy makers do produce better forecasts by considering disaggregated data and macroeconomic indicators. Furthermore, identifying key macroeconomic indicators in each origin country allows for both a better understanding of country-specific issues concerning demand for outbound tourism and a better targeting of promoting efforts concerning the tourism product of the destination country. Most importantly, this study provides evidence that it is important for destination countries to diversify their sources of tourism to account for the different factors that may impact tourist arrivals levels.

Potential avenues for future research could also include other types of disaggregation of inbound tourist arrivals by mode of travel or duration of stay, as these choices may be also impacted by the macroeconomic conditions in origin countries. What is more, future studies should further concentrate on the formulation of models which purport to combine many macroeconomic indicators in their structure. On a final note, apart from specifically focusing on one-step-ahead forecasts, attention should also be directed towards $m$-steps ahead forecasting. 


\section{References}

Akaike, H. (1974). A new look at the statistical model identification. IEEE Transactions on Automatic Control, 19(6), 716-723.

Alegre, J., Mateo, S., Pou, L. (2010). An analysis of households' appraisal of their budget constraints for potential participation in tourism. Tourism Management, $31(1), 45-56$.

Algieri, B. (2006). An econometric estimation of the demand for tourism: The case of Russia. Tourism Economics, 12(1), 5-20.

Antonakakis, N., Chatziantoniou, I., and Filis, G. (2013). Dynamic co-movements of stock market returns, implied volatility and policy uncertainty. Economics Letters, 120, 87-92.

Athanasopoulos, G., and Hyndman, R. J. (2008). Modelling and forecasting Australian domestic tourism. Tourism Management, 29(1), 19-31.

Baker, S.R., Bloom, N., and Davis, S.J. (2012). Measuring economic policy uncertainty. Unpublished Working Paper. Stanford University and University of Chicago.

Box, G.E.P. and Jenkins, G.M. (1976). Time Series Analysis: Forecasting and Control, Revised Edition, Holden-Day.

Box, G.E.P., Jenkins, G.M. and Reinsel, G.C. (2008). Time Series Analysis, Forecasting and Control ( $4^{\text {th }}$ ed). Hoboken, John Wiley \& Sons Ltd, New Jersey.

Brida, J. G., and Risso, W. A. (2011). Research note: Tourism demand forecasting with SARIMA models-the case of South Tyrol. Tourism Economics, 17(1), 209221.

Brockwell, P and Davis, R. (2009). Time Series: Theory and Methods $\left(2^{\text {nd }} \mathrm{ed}\right)$. Springer, New York.

Bull, A. (1995). The Economics of Travel and Tourism ( $2^{\text {nd }}$ ed.). Melbourne: Longman.

Burger, C. J. S. C., Dohnal, M., Kathrada, M., and Law, R. (2001). A practitioners guide to time-series methods for tourism demand forecasting - a case study of Durban, South Africa. Tourism management, 22(4), 403-409.

Chandra, S., and Menezes, D. (2001). Applications of Multivariate Analysis in International Tourism Research: The Marketing Strategy Perspective of NTOs. Journal of Economic \& Social Research, 3(1), 77-98. 
Chang, K-L., Chen, C-M., and Meyer, T.J. (2013). A comparison study of travel expenditure and consumption choices between first-time and repeat visitors. Tourism Management, 35, 275-277.

Chatziantoniou, I., Filis, G., Eeckels, B., and Apostolakis, A. (2013). Oil prices, tourism income and economic growth. A structural VAR approach for European Mediterranean Countries. Tourism Management, 36, 331-341.

Chen, R. J. (2005). Before and after the inclusion of intervention events: an evaluation of alternative forecasting methods for tourist flows. Tourism Analysis, 10(3), 269276.

Cho, V. (2001). Tourism forecasting and its relationship with leading economic indicators. Journal of Hospitality \& Tourism Research, 25(4), 399-420.

Cho, V. (2003). A comparison of three different approaches to tourist arrival forecasting. Tourism Management, 24(3), 323-330.

Colombo, V. (2013). Economic policy uncertainty in the US: Does it matter for the Euro area? Economics Letters, 121(1), 39-42.

Coshall, J. T. (2009). Combining volatility and smoothing forecasts of UK demand for international tourism. Tourism Management, 30(4), 495-511.

Croes, R.R., and Vanegas Sr., M. (2005). An econometric study of tourist arrivals in Aruba and its implications. Tourism Management, 25(6), 897-890.

Dharmaratne, G. S. (1995). Forecasting tourist arrivals in Barbados. Annals of Tourism Research, 22(4), 804-818.

Diebold, F.X., Mariano, R. (1995). Comparing predictive accuracy. Journal of Business and Economic Statistics, 13(3), 253-263.

Dritsakis, N. (2004). Cointegration analysis of German and British tourism demand for Greece. Tourism Management, 25(1), 111-119.

Eugenio-Martin, J.L., and Campos-Soria, J.A. (2014). Economic crisis and tourism expenditure cutback decision. Annals of Tourism Research, 44, 53-73.

Goh, C., and Law, R. (2002). Modeling and forecasting tourism demand for arrivals with stochastic nonstationary seasonality and intervention. Tourism Management, 23(5), 499-510.

Gounopoulos, D., Petmezas, D., and Santamaria, D. (2012). Forecasting tourist arrivals in Greece and the impact of macroeconomic shocks from the countries of tourists' origin. Annals of Tourism Research, 39(2), 641-666. 
Hadavandi, E., Ghanbari, A., Shahanaghi, K., and Abbasian-Naghneh, S. (2011). Tourist arrival forecasting by evolutionary fuzzy systems. Tourism Management, 32(5), 1196-1203.

Hao, J., Var, T., and Chon, J. (2003). A forecasting model of tourist arrivals from major markets to Thailand. Tourism Analysis, 8(1), 33-45.

Hiemstra, S. J., and Wong, K. F. (2002). Factors affecting demand for tourism in Hong Kong. Journal of Travel and Tourism Marketing, 12(1-2), 43-62.

Hylleberg, S., Engle, R.F., Granger, C.W.J. and Yoo, B.S. (1990). Seasonal integration and cointegration. Journal of Econometrics, 44(1-2), 215-238.

Kang, W., and Ratti, R.A. (2013). Structural oil price shocks and policy uncertainty. Economic Modelling, 35, 314-319.

Kim, J. H., and Moosa, I. A. (2005). Forecasting international tourist flows to Australia: A comparison between the direct and indirect methods. Tourism Management, 26(1), 69-78.

Kim, H-B., Park, J-H, Lee, S.K., and Jang, S.S. (2012). Do expectations of future wealth increase outbound tourism? Evidence from Korea. Tourism Management, $33,1141-1147$.

Kulendran, N., and Wilson, K. (2000). Modelling business travel. Tourism Economics, 6(1), 47-59.

Kulendran, N., and Witt, S. F. (2003). Forecasting the demand for international business tourism. Journal of Travel Research, 41(3), 265-271.

Law, R. (2000). Back-propagation learning in improving the accuracy of neural network-based tourism demand forecasting. Tourism Management, 21(4), 331340.

Law, R., and Au, N. (1999). A neural network model to forecast Japanese demand for travel to Hong Kong. Tourism Management, 20(1), 89-97.

Leduc, S., and Liu, Z. (2012). Uncertainty shocks are aggregate demand shocks. Federal Reserve Bank of San Francisco Working Paper, 10.

Li, G. (2004).Tourism forecasting — an almost ideal demand system approach. Ph.D. Thesis, University of Surrey.

Lim, C., and McAleer, M. (2001a). Monthly seasonal variations: Asian tourism to Australia. Annals of Tourism Research, 28(1), 68-82.

Lim, C., and McAleer, M. (2001b). Forecasting tourist arrivals. Annals of Tourism Research, 28(4), 965-977. 
Lim, C., McAleer, M., and Min, J.C.H. (2009). ARMAX modelling of international tourism demand. Mathematics and Computers in Simulation, 79(9), 2879-2888.

Ljung, G. and Box, G. (1978). On a Measure of Lack of Fit in Time Series Models. Biometrica, 65, 297-303.

Ludvigson, S.C. (2004). Consumer confidence and consumer spending. Journal of Economic Perspectives, 18(2), 29-50.

Lütkepohl, H. and Xu, F. (2012). The role of the log transformation in forecasting economic variables. Empirical Economics, 42(3), 619-638.

Newey, W. and West, K.D. (1987). A Simple Positive Semi-Definite, Heteroskedasticity and Autocorrelation Consistent Covariance Matrix. Econometrica, 55, 703-708.

Nicolau, J.L., and Mas, F.J. (2005a). Stochastic modelling: A three-stage tourist choice process. Annals of Tourism Research, 32(1), 49-69.

Nicolau, J.L., and Mas, F.J. (2005b). Heckit modelling of tourist expenditure: Evidence from Spain. International Journal of Service Industry Management, 16(3), 271-293.

Page, S., Song, H., and Wu, D.C. (2012). Assessing the impacts of the global economic crisis nad swine flu on inbound tourism demand in the United Kingdom. Journal of Travel Research, 51(2), 142-153.

Phillips, P.C.B. and Perron, P. (1988). Testing for a Unit Root in Time Series Regression, Biometrika, 75, 335-346.

Palmer, A., José Montaño, J., and Sesé, A. (2006). Designing an artificial neural network for forecasting tourism time series. Tourism Management, 27(5), 781-790.

Papatheodorou, A., Rosselló, and Xiao, H. (2010). Global economic crisis and tourism: Consequences and perspectives. Journal of Travel Research, 49, 39-45.

Pástor, L., and Veronesi, P. (2013). Political uncertainty and risk premia. Journal of Financial Economics, 110(3), 520-545.

Prideaux, B. (2005). Factors affecting bilateral tourism flows. Annals of Tourism Research, 32(3), 780-801.

Rudez, H.N. (2008). The GDP impact on international tourism demand: A Sloveniabased case. Tourism and Hospitality Management, 14(2), 217-228.

Saayman, A., and Saayman, M. (2008). Determinants of inbound tourism to South Africa. Tourism Economics, 14(1), 81-96. 
Santos, G. E. D. O. (2009). Research note: Forecasting tourism demand by disaggregated time series empirical evidence from Spain. Tourism Economics, 15(2), 467-472.

Schwarz, G. (1978). Estimating the Dimension of a Model. Annals of Statistics, 6, 461464.

Shen, S., Li, G., and Song, H. (2011). Combination forecasts of international tourism demand. Annals of Tourism Research, 38(1), 72-89.

Smeral, E., and Weber, A. (2000). Forecasting international tourism trends to 2010. Annals of Tourism Research, 27(4), 982-1006.

Song, H., and Li, G. (2008). Tourism demand modelling and forecasting-A review of recent research. Tourism Management, 29(2), 203-220.

Song, H., Lin, S., Witt, S. F., and Zhang, X. (2011). Impact of financial/economic crisis on demand for hotel rooms in Hong Kong. Tourism Management, 32(1), 172186.

Song, H., and Witt, S. F. (Eds.). (2000). Tourism Demand Modelling and Forecasting: Modern Econometric Approaches. Routledge.

Song, H., and Witt, S. F. (2006). Forecasting international tourist flows to Macau. Tourism Management, 27(2), 214-224.

Song, H., Witt, S. F., and Jensen, T. C. (2003). Tourism forecasting: accuracy of alternative econometric models. International Journal of Forecasting, 19(1), 123141.

Taylor, K., and McNabb, R. (2007). Business cycles and the role of confidence: Evidence from Europe. Oxford Bulletin of Economics and Statistics, 69(2), 185208.

Uysal, M., and O'Leary, J. T. (1986). A canonical analysis of international tourism demand.Annals of Tourism Research, 13(4), 651-655.

Vu, J. C., and Turner, L. W. (2006). Regional data forecasting accuracy: the case of Thailand. Journal of Travel Research, 45(2), 186-193.

Wan, S-K., Wang, S-H., and Woo, C-K. (2013). Aggregate vs. disaggregate forecast: case of Hong Kong. Annals of Tourism Research, 42, 434-438.

Wang, Y.S. (2009). The impact of the crisis events and macroeconomic activity on Taiwan's international inbound tourism demand. Tourism Management, 30(1), 7582. 
Wang, Y.S. (2014). Effects of budgetary constraints on international tourism expenditures. Tourism Management, 41, 9-18.

Wang, Y.S., Rompf, P., Severt, D., and Peerapatdit, N. (2006). Examining and identifying the determinants of travel expenditure patterns. International Journal of Tourism Research, 8(5), 333-347.

Wong, K. K., Song, H., and Chon, K. S. (2006). Bayesian models for tourism demand forecasting. Tourism Management, 27(5), 773-780.

Wong, K. K., Song, H., Witt, S. F., and Wu, D. C. (2007). Tourism forecasting: to combine or not to combine?. Tourism Management, 28(4), 1068-1078.

Xekalaki, E. and Degiannakis, S. (2010). ARCH Models for Financial Applications. John Wiley \& Sons Inc., New York.

Yu, G., Schwartz, Z., and Humphreys, B. R. (2007). Data patterns and the accuracy of annual tourism demand forecasts. Tourism Analysis, 12(1-2), 15-26.

Zheng, T., Bloom, B. A., Wang, X., andSchrier, T. (2012). How do Less Advanced Forecasting Methods Perform on Weekly RevPAR in Different Forecasting Horizons Following the Recession? Tourism Analysis, 17(4), 459-472. 


\section{Figures}

Figure1. Aggregate tourist arrivals from origin countries and their contribution to the total tourist arrivals. The sample period runs from January, 2003 until June, 2013.
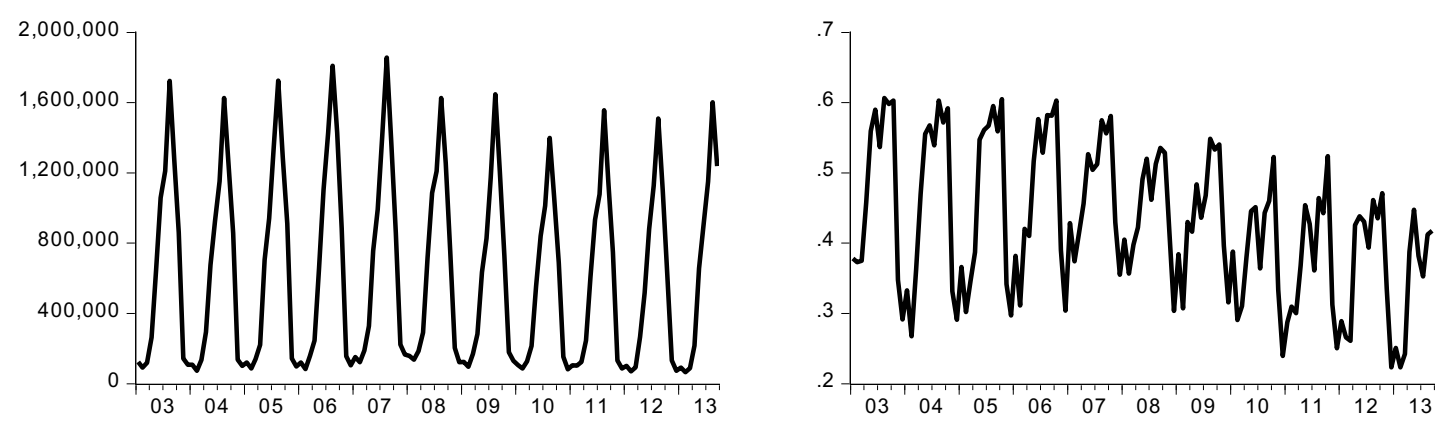

Aggregate tourist amivalsfrom the 7 origin countries

Figure2.Tourist arrivals in Greece from each origin country. The sample period runs from January, 2003 until June, 2013.
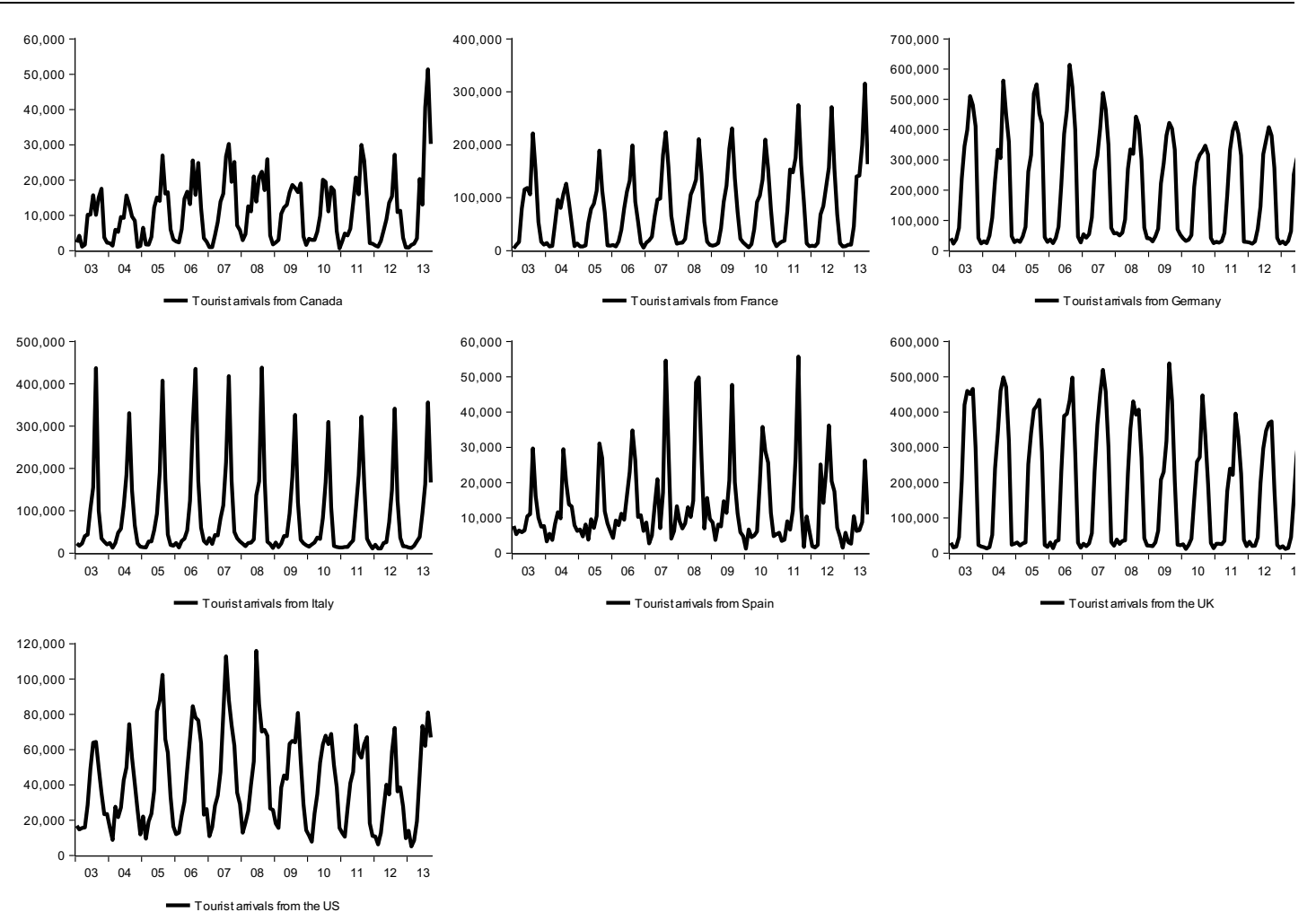
Figure3.Macroeconomic variables of the seven origin countries. The sample period runs from January, 2003 until June, 2013.
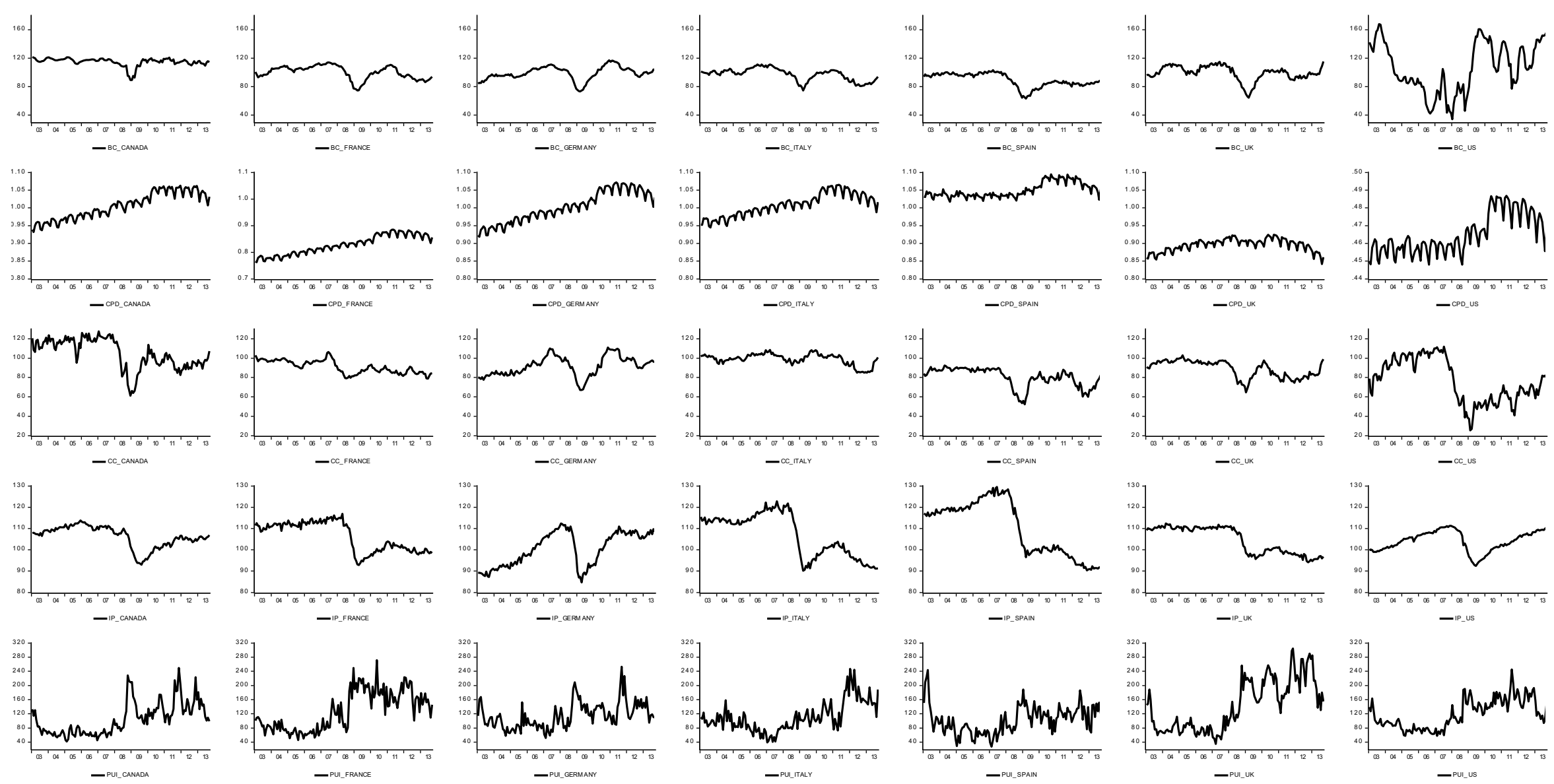

Reading along the rows we show the following macroeconomic variables: Business Confidence (BC) index, Consumer price differentials (CPD), Consumer confidence (CC) index, Industrial production (IP) index and Economic policy uncertainty (PUI) index.

Reading down the columns we show the macroeconomic variables for the following origin countries: Canada, France, Germany, Italy, Spain, the UK and the US. 
Figure4.Scatter plots of the three forecasting specifications. The sample period of the outof-sample forecasts runs from February, 2006 to June, 2013.

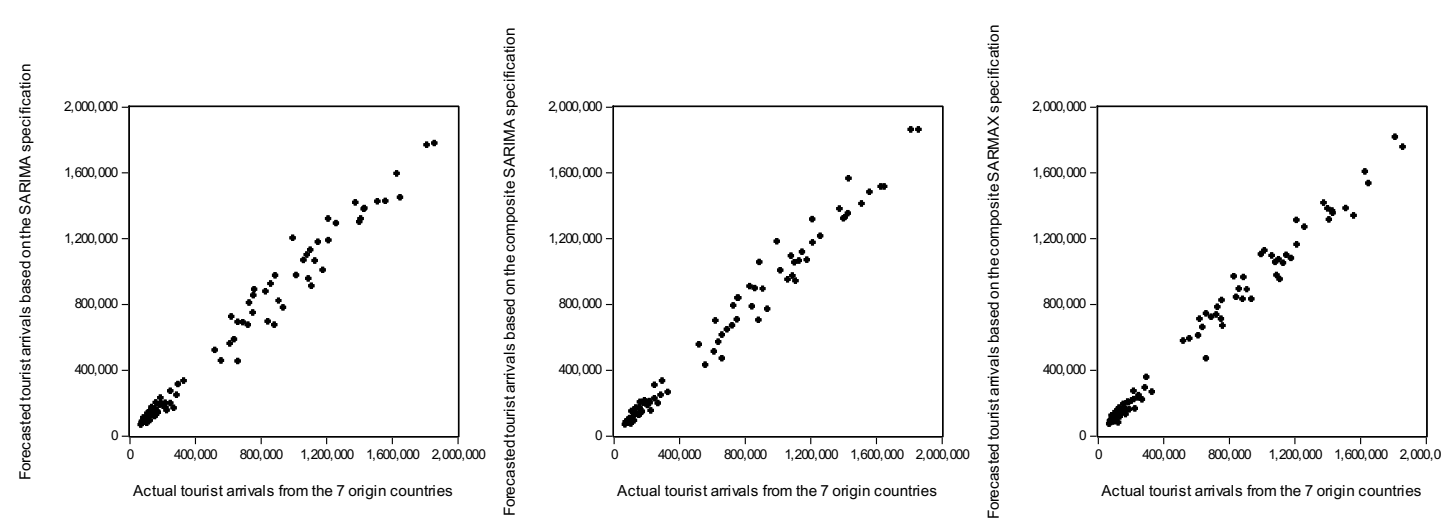

Note: Columns from left to right present the scatter plots for the forecast from the SARIMA specification, the composite SARIMA specification and the composite SARMAX specification. The $\mathrm{x}$-axes (y-axes) show the actual (predicted) values. 
Tables

\begin{tabular}{|c|c|c|c|c|c|c|c|c|}
\hline & Mean & Maximum & Minimum & Std. Dev. & Skewness & Kurtosis & Jarque-Bera & ADF-stat \\
\hline & \multicolumn{8}{|c|}{ Tourist arrivals from origin countries } \\
\hline Canada & 10987.810 & 51407.000 & 626.000 & 9131.716 & 1.233 & 5.243 & $59.740 * * *$ & 0.718 \\
\hline France & 77320.280 & 315720.000 & 4092.000 & 70868.500 & 0.958 & 3.324 & $20.281 * * *$ & 0.268 \\
\hline Germany & 206528.300 & 614134.000 & 21002.000 & 174764.700 & 0.411 & 1.715 & $12.513^{* * *}$ & -0.770 \\
\hline Italy & 87264.190 & 438110.000 & 10729.000 & 106154.100 & 1.877 & 5.807 & $118.062^{* * *}$ & -0.333 \\
\hline Spain & 12988.230 & 55705.000 & 1250.000 & 11179.630 & 1.875 & 6.509 & $141.764^{* * *}$ & -0.434 \\
\hline$U K$ & 182617.800 & 538093.000 & 11475.000 & 170887.300 & 0.457 & 1.659 & $14.163^{* * *}$ & -1.375 \\
\hline$U S$ & 41842.910 & 115923.000 & 5075.000 & 25612.050 & 0.554 & 2.501 & $7.946^{* *}$ & 0.064 \\
\hline Aggregate & 619549.200 & 1855999.000 & 66036.000 & 532613.600 & 0.583 & 2.006 & $12.615^{* * *}$ & -0.476 \\
\hline \multirow[t]{2}{*}{ Contribution } & 0.429 & 0.607 & 0.223 & 0.104 & 0.016 & 1.985 & $5.546^{*}$ & $-3.217 * * *$ \\
\hline & \multicolumn{8}{|c|}{ Log-difference of tourist arrivals from origin countries } \\
\hline Canada & 0.020 & 1.829 & -2.174 & 0.775 & -0.440 & 3.521 & $5.567^{*}$ & $-6.003 * * *$ \\
\hline France & 0.029 & 1.767 & -2.006 & 0.731 & -0.255 & 3.287 & 1.820 & $-5.896^{* * *}$ \\
\hline Germany & 0.019 & 1.414 & -2.378 & 0.722 & -1.356 & 5.685 & $77.680^{* * *}$ & $-5.559 * * *$ \\
\hline Italy & 0.016 & 1.445 & -1.870 & 0.707 & -0.545 & 2.602 & $7.180^{* *}$ & $-7.100 * * *$ \\
\hline Spain & 0.003 & 2.401 & -2.004 & 0.748 & 0.165 & 3.356 & 1.255 & $-7.707 * * *$ \\
\hline$U K$ & 0.019 & 2.114 & -2.590 & 0.874 & -0.792 & 4.739 & $29.489^{* * *}$ & $-5.526^{* * *}$ \\
\hline$U S$ & 0.011 & 1.149 & -1.303 & 0.487 & -0.184 & 2.813 & 0.907 & $-5.216^{* * *}$ \\
\hline Aggregate & 0.018 & 1.160 & -1.843 & 0.641 & -0.999 & 4.173 & $28.622 * * *$ & $-5.699 * * *$ \\
\hline
\end{tabular}




\begin{tabular}{|c|c|c|c|}
\hline \multirow[b]{2}{*}{$\begin{array}{c}\text { Country of } \\
\text { Origin }\end{array}$} & \multirow[b]{2}{*}{$\begin{array}{c}\text { SARIMA } \\
\text { Specification }\end{array}$} & \multicolumn{2}{|c|}{ Forecast Evaluation Criteria } \\
\hline & & $\sqrt{h^{-1}} \sum_{t=1}^{h}\left(y_{t+1}-y_{t+1 \mid t}\right)^{2}$ & $h^{-1} \sum_{t=1}^{h}\left|y_{t+1}-y_{t+1 \mid t}\right|$ \\
\hline \multicolumn{4}{|c|}{ Aggregate tourist arrivals (SARIMA specification) } \\
\hline $\begin{array}{c}\text { Total } \\
\text { Forecast }\end{array}$ & $\operatorname{SARIMA}(2,1,0)(1,1)$ & 74,035 & 51,893 \\
\hline \multicolumn{4}{|c|}{$\begin{array}{l}\text { Disaggregated tourist arrivals without exogenous macroeconomic variables } \\
\text { (composite SARIMA specification) }\end{array}$} \\
\hline $\begin{array}{l}\text { Composite } \\
\text { Forecast }\end{array}$ & $\begin{array}{l}\text { The average forecast from } \\
\text { the models below }\end{array}$ & 69,296 & 50,282 \\
\hline Canada & $\operatorname{SARIMA}(1,1,1)(0,2)$ & 5,250 & 3,611 \\
\hline France & $\operatorname{SARIMA}(0,1,1)(1,1)$ & 20,241 & 13,597 \\
\hline Germany & $\operatorname{SARIMA}(0,1,0)(1,1)$ & 40,132 & 26,352 \\
\hline Italy & $\operatorname{SARIMA}(2,1,0)(0,2)$ & 29,789 & 16,645 \\
\hline Spain & $\operatorname{SARIMA}(2,1,0)(0,2)$ & 8,370 & 5,674 \\
\hline UK & $\operatorname{SARIMA}(0,1,1)(1,1)$ & 38,831 & 23,126 \\
\hline US & $\operatorname{SARIMA}(1,1,2)(0,2)$ & 12,843 & 9,218 \\
\hline
\end{tabular}

Disaggregated tourist arrivals with exogenous macroeconomic variables (composite SARMAX specification)

\begin{tabular}{cccc}
\hline $\begin{array}{c}\text { Composite } \\
\text { Forecast }\end{array}$ & $\begin{array}{c}\text { The average forecast from } \\
\text { the models below }\end{array}$ & $\mathbf{6 2 , 7 3 3}$ & $\mathbf{4 5 , 7 1 1}$ \\
Canada & SARMAX $(1,0)(0,2)$-CC & $\mathbf{4 , 9 0 6}$ & $\mathbf{3 , 4 8 0}$ \\
France & SARMAX $(2,0)(1,1)-$ CPD & $\mathbf{1 8 , 8 9 3}$ & $\mathbf{1 2 , 9 2 6}$ \\
Germany & SARMAX(0,1)(1,0)-CPD & $\mathbf{3 4 , 5 0 1}$ & $\mathbf{2 4 , 5 9 2}$ \\
Italy & SARMAX(0,0)(1,1)-IP & $\mathbf{2 2 , 4 8 3}$ & $\mathbf{1 3 , 8 4 8}$ \\
Spain & SARMAX(0,0)(0,2)-IP & $\mathbf{6 , 9 4 1}$ & $\mathbf{5 , 1 0 5}$ \\
UK & SARMAX(1,0)(1,1)-CC & $\mathbf{3 5 , 8 1 4}$ & $\mathbf{2 2 , 4 8 6}$ \\
US & SARMAX $(1,1)(1,0)$-PUI & 12,956 & 9,353 \\
\hline
\end{tabular}

Values report number of tourist arrivals.

Bold face fonts present the best performing model.

Consumer confidence (CC) index, Consumer price differentials (CPD), Industrial production (IP) index and Economic policy uncertainty (PUI) index 
Table 3. The DM test statistics for testing the null hypothesis that Model $\mathrm{A}$ is of equal predictive ability as Model B. The evaluation criterion is based on the squared predicted error;

\begin{tabular}{cccc}
$\Psi_{t}=\left(y_{t+1}-y_{t+1 \mid t}\right)^{2}$. & & \\
\hline Model A & Model B & DM Statistic & $p$-value \\
\hline $\begin{array}{c}\text { Forecast from } \\
\text { composite }\end{array}$ & $\begin{array}{c}\text { Forecast from } \\
\text { SARIMA }\end{array}$ & -0.985 & 0.3272 \\
SARIMA & Forecast from & -1.344 & \\
$\begin{array}{c}\text { Forecast from } \\
\text { composite }\end{array}$ & $\begin{array}{c} \\
\text { SARMAX }\end{array}$ & & 0.1824 \\
$\begin{array}{c}\text { Fomposite SARIMA } \\
\text { composite }\end{array}$ & Forecast from & -2.669 & 0.0090 \\
SARMAX & SARIMA & & \\
\hline
\end{tabular}

\begin{tabular}{|c|c|c|c|}
\hline Model A & Model B & DM Statistic & $p$-value \\
\hline $\begin{array}{c}\text { Forecast from } \\
\text { composite } \\
\text { SARIMA }\end{array}$ & $\begin{array}{c}\text { Forecast from } \\
\text { SARIMA }\end{array}$ & -0.448 & 0.6549 \\
\hline $\begin{array}{l}\text { Forecast from } \\
\text { composite } \\
\text { SARMAX }\end{array}$ & $\begin{array}{c}\text { Forecast from } \\
\text { composite SARIMA }\end{array}$ & -1.293 & 0.1992 \\
\hline $\begin{array}{l}\text { Forecast from } \\
\text { composite } \\
\text { SARMAX }\end{array}$ & $\begin{array}{c}\text { Forecast from } \\
\text { SARIMA }\end{array}$ & -3.534 & 0.0007 \\
\hline
\end{tabular}

